\title{
Using contests to promote coordinated control of invasive species: An experimental evaluation
}

Discussion Paper no. 2021-16

\section{Stefan Meyer, Paulo Santos and Chitpasong Kousonsavath}

\begin{abstract}
:
We experimentally evaluate the effect of competing for a prize on the coordinated control of invasive species in the presence of externalities. We offered prizes (merit, monetary and a combination of both) to the best performer in a contest aimed at promoting the control of rodent pests, an invasive species that is responsible for large losses in stored grain. Only monetary prizes are capable of promoting behavioral change, with relatively large effects: households in villages where prizes were offered reported losses in storage that are $25 \%$ lower than in control villages. The effect is a non-linear function of prize, with only intermediate size prizes leading to reductions in storage losses. Spillovers matter greatly, with non-participants in the contest benefiting almost as much as participants, highlighting the importance of externalities. Avoided losses are large enough to drive a reduction in rice prices in seasonally isolated markets.
\end{abstract}

Keywords: contests, invasive species, spillovers, food security

JEL Classification: Q56, Q12

Stefan Meyer: Monash University (email: stefan.meyer@monash.edu); Paulo Santos: Monash University (email: paulo.santos@monash.edu); Chitpasong Kousonsavath: National University of Laos (email: kousonsavath.chit@gmail.com).

(C) The authors listed. All rights reserved. No part of this paper may be reproduced in any form, or stored in a retrieval system, without the prior written permission of the author. 


\title{
Using contests to promote coordinated control of invasive species: an experimental evaluation
}

\author{
Stefan Meyer* Paulo Santos ${ }^{\dagger}$ Chitpasong Kousonsavath ${ }^{\ddagger}$
}

First draft: October 2020

This draft: October 2021

\begin{abstract}
We experimentally evaluate the effect of competing for a prize on the coordinated control of invasive species in the presence of externalities using a framed field experiment. We offered prizes (merit, monetary and a combination of both) to the best performer in a contest aimed at promoting the control of rodent pests, an invasive species that is responsible for large losses in stored rice, in our context (Lao PDR) and more generally in Asia. Only monetary prizes are capable of promoting behavioral change, with relatively large effects: households in villages where prizes were offered reported losses in storage that are $25 \%$ lower than in control villages. The effect is a non-linear function of prize, with only intermediate size prizes leading to reductions in storage losses. Spillovers matter greatly, with non-participants in the contest benefiting almost as much as participants, highlighting the importance of externalities. Avoided losses are large enough to drive a reduction in rice prices in seasonally isolated markets.
\end{abstract}

Keywords: invasive species, contests, spillovers

\footnotetext{
${ }^{*}$ Monash University

${ }^{\dagger}$ Monash University

${ }^{\ddagger}$ National University of Laos
} 


\section{Introduction: rats and men}

There is a growing recognition of the negative ecological and economic impacts of invasive species, which are perhaps better documented in the agricultural and forestry sectors (??). Invasive species' dispersion over the landscape, and corresponding impact on large numbers of individual landowners, creates the need for coordinated control, which is not aproblematic: when deciding how to allocate resources to control activities, private incentives to reduce own damage do not take into account the localized positive externalities generated by those same activities, that benefit one's neighbors (????). ${ }^{1}$ Awareness of those externalities creates the incentive to free-ride on the efforts of others, that turn the success of a control strategy dependent on the actions of the affected decision-maker who contributes least (??).

Suggested solutions to the under provision of control involve, for example, neighbours in unaffected properties paying owners of affected properties for control activities (?????). To our knowledge, there are no practical applications of this decentralized approach, and control activities usually rely on outside payments (for example, bounties). We study one alternative solution to this problem: offering a prize to the best performer in a contest aimed at controlling a pest, which we implement in the context of rodent control, an old (and seemingly intractable) problem.

Rodents are the most species rich order among mammals (2277 out of 5419 species, or $42 \%$ ). This richness, together with a long history of as-

\footnotetext{
${ }^{1}$ Obviously, these externalities can also be negative, given the possibility of remigration to an area where the species was already controlled, with invasive species moving from areas with high population pressure where control activities were less effective (?).
} 
sociation with humans (?), likely explains their widespread impacts that range from human health (?) and ecosystem degradation (?) to agricultural production. ${ }^{2}$ In Asia, estimates of the damage to agricultural production alone suggest that, on average, $5-10 \%$ of the rice harvest is lost every year, an amount that would be enough to feed approximately 200 million people (????). ${ }^{3}$ Post-harvest losses have received less attention, but existing estimates suggest they are likely to be equivalent to pre-harvest losses (????) or potentially even larger (in value) if degradation in quality is taken into account (?).

Although only a small number of species (less than 10\%) can be considered a pest, the black rat (Rattus rattus), also known as house or ship rat, is clearly among them. ${ }^{4}$ Originating from India and the coastal areas of South-East Asia, this species spread through mainland Asia and then the rest of the world, accompanying the expansion of human habitats and the increasing trade of goods by ships (??) to become the main rodent pest species in the world (?), including in northern Lao PDR, the setting of our

\footnotetext{
${ }^{2}$ Although rodent control swiftly followed the association with humans, it was never very successful, possibly reflecting rodents' genetic and behavioural responses to control activities. Rodents are unique among vertebrates in exhibiting both resistance (?) and neophobia (?). The concurrent presence of these traits may help explain why rodents are persistently seen, in popular culture, as capable of outsmarting humans, of which the most widely known example would be the Benjy and Frankie mice in Douglas Adams' Hitchhikers Guide to the Galaxy. For laboratory evidence supporting the hypothesis that rodents are quicker learners than humans, see ?.

${ }^{3}$ The impact on food security becomes particularly noticeable during outbreaks that lead to widespread famines and hunger. ? presents a, perhaps extreme, example of the consequences of such outbreaks in his discussion of the political consequences of a severe regional famine in 1958-59, occasioned by one such outbreak in northeastern India, which led to subsequent civil unrest, a prolonged civil war against the central Indian government and the creation of Mizoram State in 1986.

${ }^{4}$ See ? for a recent review of of the relative importance of different rodent species as pests.
} 
analysis (????).

The persistence of large losses due to this pest cannot be justified by lack of technological knowledge on how to control rodents (?), and it should instead be traced to its reproductive behaviour, in particular high litter size, short gestation period and early sexual maturity. One female black rat can have up to 5 litters during its life (one year), each with up to 10 pups (?), that become sexually mature at 3 to 4 months and start reproducing whenever food is available (?). Female black rats are found to be pregnant at all times of the year, with the highest pregnancy rates of $85 \%$ found during the dry season, in the village habitats, where rodents move to after the harvest (?). As a result, if some farmers do not act to control rodent reproduction (either by protecting their rice, hence limiting access to food, and/or culling rodents), black rats will quickly multiply, rendering any individual effort almost useless. The foraging behavior of this species further complicates the effectiveness of its control: black rats forage within a limited radius (around 100m) of their nests (?). ${ }^{5}$ As a result, control of this pest will have limited benefits outside this distance. The challenge then is how to coordinate multiple farmers into rodent control, over an extended period of time, as it is recognized in the literature (???).

The approach to promoting coordinated control that we pilot and evaluate is a time-limited contest where those who cull most rodents win a prize. Because participants know the end date of the contest, when the winner would be decided, this should encourage them to simultaneously allocate

\footnotetext{
${ }^{5}$ See ? for information of the foraging behaviour of other rodent species, that cover similar distances/areas.
} 
time and other resources to rodent control - ie, coordinated rodent control - while the prize aims at rewarding participants for the positive spillovers earned by those who don't engage in the control of this pest.

This paper presents the results of an experimental evaluation of this approach. In the next section we present the details of the contest that we promoted, including the description of its rules and its implementation. By design, the contest required no specific organizational skills, while monitoring and enforcement of its rules was delegated to villagers themselves. This simplicity makes it potentially scalable, if proven effective. We also contrast it with some of the alternative approaches that have been used to address this problem.

Three types of prizes (merit, monetary and a combination of both) were randomly offered in 27 villages, to be contrasted with the "status quo" in other 9 villages. The data is presented in more detail in section 3, while the main results are presented in section 4 . The intention-to-treat estimates show that monetary prizes are an effective way to promote coordinated control of this pest, but that merit prizes do not have an effect on storage losses. On average, the contest reduces losses to stored grain by $15 \mathrm{~kg}$ per household during the period of its implementation (approximately 4 months), an amount that is equivalent to approximately $25 \%$ of the average losses in control villages. These gains translate into an estimated Benefit-Cost Ratio of 4.95, making this approach a simple and effective way to increase the availability of rice between two harvests. The relation between losses and the value of monetary prize is non-linear, with only moderate size prizes proving to be effective. This result seems to be explained by the fact that 
larger prizes, by encouraging higher effort at the start of the contest, seem to be accompanied by higher probabilities of dropping out of the contest (or lower effort) in latter periods by those participants who may consider it unlikely to win the prize.

As expected, spillover effects from the contest are important, with households that do not participate in the contest benefitting almost as much as those that participated, an effect that is driven by having neighbours (ie, households with main rice storage within a 100 meters radius of one's rice storage) who participate. In villages without road access during the wet season (and, consequently, with isolated markets during that time of the year), the reduction in losses is large enough to lead to a reduction in local prices at the end of the wet season (when household stocks from previous harvest are becoming exhausted), further increasing the benefits of this intervention for food insecure households. We conclude with some suggestions for future work.

\section{Rodent damage and control}

We designed and piloted a time-limited contest where those who cull most rodents win a prize. The design of the contest was guided by two principles: firstly, to make it as simple as possible, in order for it to be scalable (in particular, and given the scarcity of qualified human resources in the administration, by minimizing its reliance on external human resources) and, secondly, to reduce the likelihood of negative impacts in the local ecosys- 
tem. ${ }^{6}$ As a result, both the rules of the contest and its implementation were very simple.

The contest was initiated with a relatively short village meeting (typically less than 90 minutes), during which the contest rules were presented and questions were answered. ${ }^{7}$ The contest would be limited in time, implemented between January and mid-April 2018 (to coincide with Lao New Year). The number of culled rodents would be counted every month, at a pre-agreed day (e.g. last Saturday of the month). To minimize its ecological impact, a few simple rules were imposed: only black rats were to be culled, in villages and fields but not in forests, and with no use of rodenticide. ${ }^{8}$

Given it would be extremely onerous to monitor and enforce these rules from the outside it was decided from the onset that they would be locally monitored and enforced. The possibility of excluding participants who were found to be not complying with these rules was clearly stated and presented in moral terms of "a neighbour cheating on another neighbour" (rather than on the research team). Following this presentation, villagers were asked to decide whether the contest would be run in their village (none rejected) and, if willing, to select a trusted community member to keep a tally of

\footnotetext{
${ }^{6}$ There are several other uses of this approach to the control of invasive species but, to the best of our knowledge, none has been evaluated. ? suggests the use of tournaments to control the expansion of lionfish in coral reefs, but we have no information on whether this approach was implemented. The Florida Fish and Wildlife Conservation Commission has run, since 2013, the Python Challenge ${ }^{\mathrm{TM}}$ that pays a prize (worth $\$ 2,000$ in 2019 ) to the individual who captures the largest Burmese python and an ATV to the individual who captures most snakes. The popular press also reported similar competitions in Bangladesh (?) and in The Philippines (?).

${ }^{7}$ The protocol of the village meeting is presented in Appendix A.

${ }^{8}$ These rules follow, in a simplified way, many of the recommendations and conclusions of the literature on Ecologically-Based Rodent Management (see ?, for an earlier discussion), which presents obvious analogies with Integrated Pest Management (IPM), developed as a response to the increasing use of chemical products in pest control.
} 
participants and their performance. Once the meeting was concluded, the project team distributed promotional material that summarised the above information.

We defined two types of prizes: a merit award (a certificate) and monetary (with values of 250,000 LAK, 500,000 LAK and 750,000 LAK). ${ }^{9}$ In villages where a monetary award was offered, participants who culled a minimum number of rodents (set at 100) were also eligible to participate in a lottery with a prize of 100,000 LAK. It is important to note that the objective of the contest was not to determine the best performer, rather it aimed at motivating as large a number of people as possible to participate into rodent control. The lottery was introduced as one way to keep participants engaged in the competition even if it became apparent that they would not be the winners of the main prize.

Merit awards are a common way (maybe even the default way) of addressing a variety of environmental problems in northern Lao PDR, even in the absence of any evidence supporting their use. Hence, this study has direct implications on what to expect from existing approaches. More generally, different types of prizes address different motivations that, given the importance of externalities, may matter in this context (see ? for a recent review): while merit awards address intrinsic motivations, monetary prizes would address extrinsic motives.

There are two potential alternatives to the approach we pilot. The first alternative is the implementation of bounty schemes, with several historical examples of its use in rodent control, including in Lao PDR and neighbour-

\footnotetext{
${ }^{9}$ At the start of the the contest, 1 USD $\sim 8,900 \mathrm{LAK}$.
} 
ing Vietnam (?). These experiences can be used to illustrate some of its shortcomings.

The first is the potential negative environmental consequences of bounties, as they may motivate the culling of non-pest rodents, some of which provide important ecosystem services (?). The second shortcoming is the well-known "cobra effect": payments that are enough to encourage time intensive activities such as hunting and culling pests are also likely to cover the costs of "farming" the species. This is a general concern with harvesting programs (?), as they may create an interest in maintaining the species that it aims to control. ? documents its importance in the case of rodent control. ${ }^{10}$ Finally, bounties are an open funding commitment that may limit its attractiveness to cash-constrained programs or organizations.

The second alternative approach is to coordinate behavioral change via communication campaigns. ? report on the effect of information campaigns in the mass media in The Philippines. They find positive effects on the perception and knowledge about rodent damage, as well as on yield. However, the reliance on a comparison between farmers who heard about the campaign and those who did not hear about it, using cross-sectional data, raises questions about the importance of self-selection. ? report on the use of existing local governance structures (local leaders) as promoters of participation on a variety of rodent control activities in Lao PDR. It is difficult to

\footnotetext{
${ }^{10}$ In 1902, the French administration in Hanoi was confronted with an increasing rat population in the newly installed sewage system. The administration responded with a payment for each rat tail that was submitted at their offices. Despite its apparent immediate success (documents show that on one day more than 20,000 rats were killed), soon people were found breading rats at the same time as rats without tails were found in the city. The scheme was rapidly considered a failure and abandoned.
} 
judge whether participation in such activities is completely voluntary and whether it leads to improvements in living conditions, although they report reductions in losses due to rodents even if, again, it is difficult to quantify whether selection plays a role in the conclusions. ${ }^{11}$

\section{$3 \quad$ Research design and data}

We use a clustered randomized control trial to evaluate the impact of this contest. Data was collected in 36 villages, of which 27 were randomly allocated to treatment, 9 to each of the three treatment arms (money, merit and both), with the remaining 9 villages allocated to the control group. In each village we interviewed 12 households, randomly selected from the village roster. We collected information on self-assessed post-harvest losses from rodents (our main outcome of interest) and practice of rodent control during the dry season. In addition, we collected information on household characteristics that may influence opportunity cost of time, including demographic characteristics and wealth (land and assets).

The data also allow us to characterize the knowledge and practices of the respondents regarding rodent control in the dry season. The first conclusion is that damage is widespread: only a small fraction of households (less than $6 \%$ ) declared suffering no damage to stored rice in the previous dry season, with most households (57\%) declaring that they suffered a large damage. By comparison, the number of households who suffered damage to stored rice

\footnotetext{
${ }^{11}$ ? conclusions rely on a matched design, where balance of initial conditions relies on the assumption that proximity between matched pairs of treated and control villages creates balance. However, evidence in support of such assumption is not presented.
} 
due to mould or insects is much more limited ( $11 \%$ and $41 \%$, respectively) and, conditional on suffering some damage, most households judged it to be smaller than the damage caused by rodents. Overall, these numbers confirm what has been described in other work in this region: rodents are a major cause of loss of grain and, as a consequence, a threat to food security. Although estimates of losses must be taken with some caution given the large time lag between their occurrence and data collection (approximately 8 months), our data also allows us to estimate the extent of this damage: approximately $53 \mathrm{~kg}$ per household, the equivalent to 3 weeks of average household consumption. ${ }^{12}$ The second conclusion is that rodent control is widespread, and mostly reliant on the use of break-back traps: only $10 \%$ of the households declared not practicing any form of rodent control and, conditional of practicing some form of rodent control, $99 \%$ use traps, while digging burrows (the next most popular form of control) is practiced by only $2 \%$ of the respondents.

Finally, we can also say something about local knowledge about the effects of rodent control. Only $25 \%$ of the respondents believe that there is a movement of rodents from village to fields after the start of the wet season (while 55\% do not believe in such link and 20\% don't know), and most households consider damage during wet season (in the field) to be larger than in storage. Households are strongly aware of how interdependent they are with respect to their neighbours: $65 \%$ agree that their own efforts are more effective if neighbours also practice rodent control (12\% don't know)

\footnotetext{
${ }^{12}$ Average consumption of rice per capita in Laos is $163 \mathrm{~kg} /$ year (?). Average household size in our sample is 6 people.
} 
while a slightly larger number ( $80 \%$ of the respondents) are convinced that their neighbours benefit from their own effort (15\% don't know).

Taken together, these results suggest two problems and one opportunity to promote rodent control during the dry season. The opportunity is that losses seem relatively large: effective ways to reduce this damage could go some way into improving living standards. The problems are twofold: respondents seem to downplay its importance (when compared with the extent of damage during wet season) and seem largely unaware of the link between pest pressure across different seasons 9ie, they seem ignorant of the spatiotemporal dynamics of the pest), while being acutely aware of the presence of externalities (that require coordination to be adequately addressed).

Summary statistics for the baseline data, collected in November-December 2017, are presented in Table 1. Our data shows that the randomized allocation of the three types of prizes (merit, monetary, both) succeeded in achieving balance for those variables that are likely to matter most for individual participation in the contest and for post-harvest losses. This conclusion is reinforced by an $F$-test of the joint significance of these variables in explaining treatment status. There are some meaningful differences that are, in general, relatively minor and would, if anything, bias our estimates downward. ${ }^{13}$ We present results with control variables in the Appendix, and in no case are our conclusions substantively changed by their inclusion. ${ }^{14}$

The second threat to internal validity of our estimates is attrition. We

\footnotetext{
${ }^{13}$ This is true also when we disaggregate monetary prizes in the three values that were offered, although in this case results need to be considered with more care, given the small number of villages in each treatment arm. See Tables B3 and B4.

${ }^{14}$ See Table B5.
} 


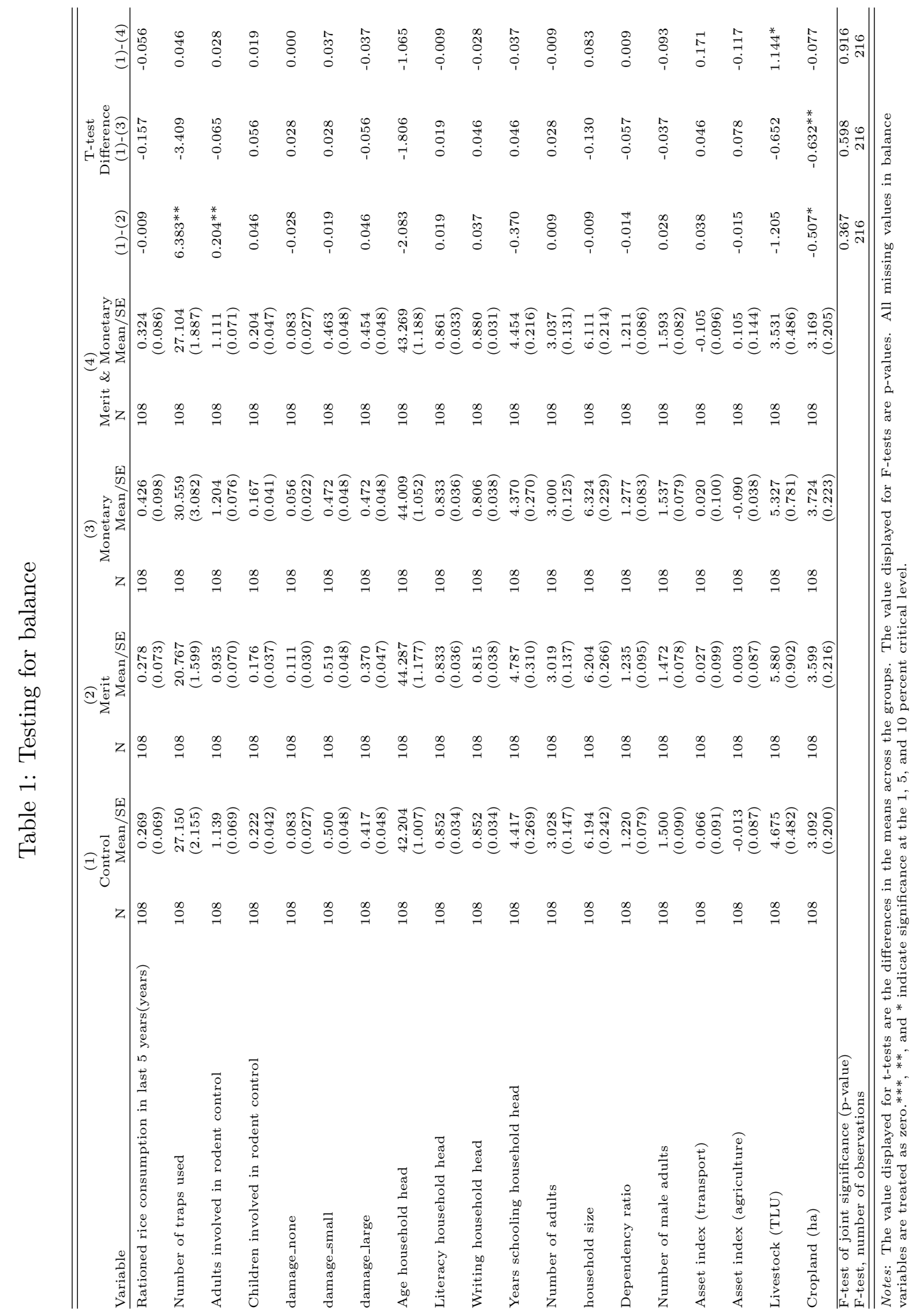


were not able to re-interview 67 respondents, a relatively large share (15.5\%) of those who were interviewed at baseline, which is likely explained by the fact that the endline survey was fielded close to the start of the main cropping season, when many respondents spend much time in their plots and away from home. ${ }^{15}$ As shown in Table 2, probability of attrition is not correlated with treatment status in any of the treatment arms.

In addition to the household data we also have information on the number of participants and the number of culled rodents throughout the duration of the contest. Some summary statistics are presented in Table 3.

On average, approximately 10 households per village participated in the contest ( $14 \%$ of the households in a village), a small but non-negligible share of the population. However, there are important differences: participation rate in villages where larger monetary prizes were offered was more than the double the participation rate in villages allocated to the merit award, while the smallest prize attracted a participation rate that is similar to merit awards. Similarly, there are differences in terms of effort (number of rodents culled per participant), which is clearly lower in those villages where only the merit award was offered, and higher in the highest prize (with the other two prizes somewhere in between, at a similar level).

This data allow us to discuss two other aspects that may matter to explain the impact of this contest: the timing of the culling (earlier reductions in pest pressure should lead to higher reductions in losses) and its con-

\footnotetext{
${ }^{15}$ To test the importance of selective attrition, we estimate the following equation:

$$
A_{i}=\beta_{0}+\beta_{1} T_{i}+\epsilon_{i}
$$

where $A_{i}$ is an indicator variable that is equal to 1 if the household was interviewed at baseline but not at endline and $T_{i}$ is a vector of treatment indicators.
} 
Table 2: Explaining attrition as a function of treatment status

\begin{tabular}{|c|c|c|}
\hline & $\begin{array}{c}(1) \\
\text { att_3 }\end{array}$ & $\begin{array}{c}(2) \\
\text { att_4 }\end{array}$ \\
\hline merit & $\begin{array}{c}-0.028 \\
(0.109)\end{array}$ & $\begin{array}{l}-0.028 \\
(0.110)\end{array}$ \\
\hline money & $\begin{array}{c}-0.139 \\
(0.104)\end{array}$ & \\
\hline merit + money & $\begin{array}{c}0.102 \\
(0.121)\end{array}$ & \\
\hline $250,000 \mathrm{LAK}$ & & $\begin{array}{c}-0.157 \\
(0.105)\end{array}$ \\
\hline $500,000 \mathrm{LAK}$ & & $\begin{array}{l}-0.102 \\
(0.105)\end{array}$ \\
\hline $750,000 \mathrm{LAK}$ & & $\begin{array}{l}-0.157 \\
(0.112)\end{array}$ \\
\hline m250wme & & $\begin{array}{c}0.167 \\
(0.151)\end{array}$ \\
\hline m500wme & & $\begin{array}{c}0.111 \\
(0.128)\end{array}$ \\
\hline m750wme & & $\begin{array}{c}0.028 \\
(0.128)\end{array}$ \\
\hline Constant & $\begin{array}{c}0.213^{* *} \\
(0.102)\end{array}$ & $\begin{array}{c}0.213^{* *} \\
(0.102)\end{array}$ \\
\hline Observations & 432 & 432 \\
\hline
\end{tabular}


Table 3: Participation in contest: M\&E data

\begin{tabular}{lcccc}
\hline \hline & Merit & \multicolumn{3}{c}{ Money } \\
& & 250,000 & 500,000 & 750,000 \\
\hline Participants (average number per village) & 7.1 & 6.2 & 14.2 & 10.3 \\
Participants (\% village population) & 9.2 & 9.3 & 21.3 & 19.2 \\
Culled rodents (number) & 315 & 666 & 1501 & 1705 \\
Effort (rodents/participant) & 44 & 107 & 106 & 166 \\
\hline Villages (number) & 9 & 6 & 6 & 6 \\
\hline \hline
\end{tabular}

centration (higher concentration of culling reflects that a small number of participants are responsible for most of the reduction in pest pressure which, given the limited mobility of rodents, should lead to smaller reductions in losses).

The effect of the different monetary prizes on these variables can be summarised in Figure 1. ${ }^{16}$ Higher prizes lead to higher effort in the first month of the competition, both in terms of the overall number of culled rodents (Figure 1a) and in terms of maximum number of culled rodents in each village (Figure 1b). Given the distribution of effort in the first month of the competition, a much larger number of initial participants performed much worse than the initial best performer in villages that were offered the largest prize of $750,000 \mathrm{LAK}$ (Figure 1c). This distance is associated with both the probability of dropping out of the contest after the first month and the effort in the remaining of the competition (Figure 1d). ${ }^{17}$ Overall, this data suggests that the relation between the value of the prize and sustained participation and effort in the contest throughout its duration (that would

\footnotetext{
${ }^{16}$ See also Table B1. To avoid overcrowding this Figure, we present only the results for the lowest $(250,000 \mathrm{LAK})$ and highest $(750,000 \mathrm{LAK})$ monetary prizes, given that behavior in the intermediate prize is somewhat in between of these two.

${ }^{17}$ See results in Table B2.
} 
Figure 1: The potential discouraging effects of higher prizes

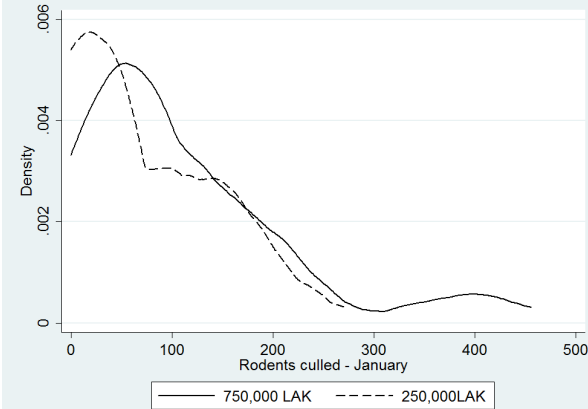

(a) Effort, month 1: 250,000 LAK vs 750,000 LAK

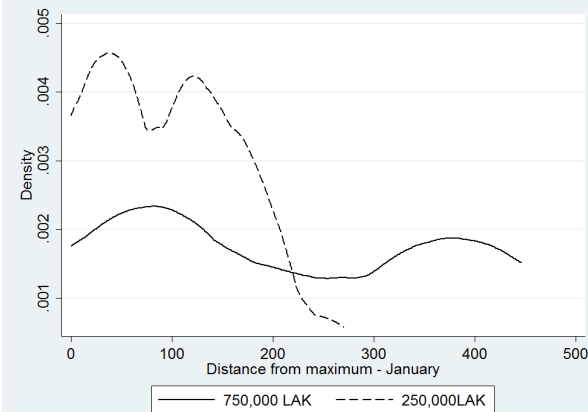

(c) Distance to maximum: 250,000 LAK vs $750,000 \mathrm{LAK}$

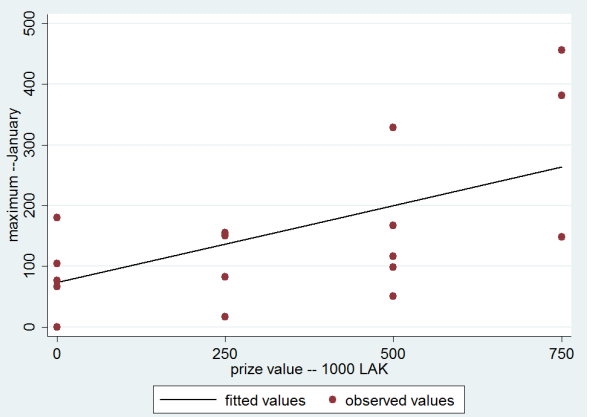

(b) Maximum number of rodents culled in first month per value of prize

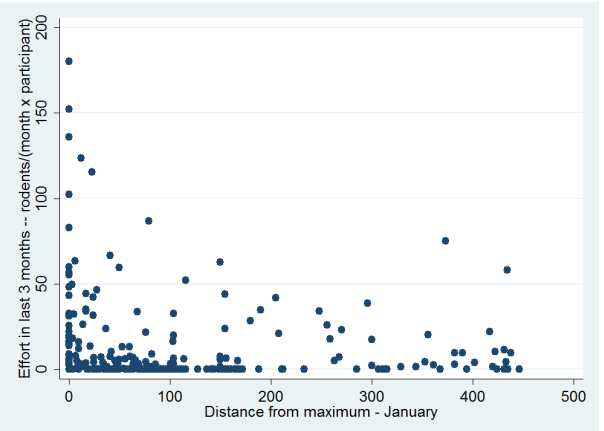

(d) Effort in last 3 months vs distance to maximum in first month

Include explanation of these figures here

lead to larger reductions in storage losses) is ambiguous: higher prizes may not lead to larger reductions in losses if they discourage sustained culling of rodents by those participants who may consider that their chances of winning are exceedingly low. 


\section{Main results}

Randomization of treatment status allows us to estimate the effect of this contest on any outcome of interest using a difference-in-difference specification:

$$
y_{i v t}=\beta_{0}+\beta_{1} T_{v}+\beta_{2} t+\beta_{3}\left(T_{v} \times t\right)+\epsilon_{i v t}
$$

where $y_{i v t}$ is the value of the outcome for household $i$ in village $v$ at time $t$ and $T_{v}$ is a vector of treatment indicator variables equal to 1 if a household lives in a village allocated to one of the treatment arms (and 0 otherwise). We mostly care about our estimates of $\beta_{3}$ which we interpret as the Intent To Treat (ITT). We report standard errors clustered at the village level and also wild-bootstrap $p$-values (?) to address concerns with the relatively small number of clusters. As outcomes, we analyze the impact of the contests on rodent effort (number of traps used, labor allocated to rodent control and number of rodents culled) and damage to stored rice (our main variable of interest).

Table 4, panel A, presents the ITT estimates of the effect of this intervention when we consider the two types of prizes (money, merit) and their possible interaction. ${ }^{18}$ The conclusions are relatively straightforward. Although merit awards seem to promote behavioral change (in terms of use of traps and allocation of children's time), these changes do not translate

\footnotetext{
${ }^{18}$ The variable Merit takes the value of 1 if the household is in a village where this prize is offered, either alone or together with monetary awards. The variable Money is similarly defined. The possibility of an interaction between the two types of incentives is captured by the coefficient on the variable Merit + Money, which is an indicator variable that takes the value of 1 if the household is in a village where both types of prizes are offered.
} 
into noticeable reductions in losses in stored rice. Monetary awards lead to both types of changes, with significant reductions in losses $(-15.5 \mathrm{~kg}$ per household, approximately $25 \%$ of the losses in the control group). There are no clearly identifiable gains from combining the two types of awards.

The effects of monetary prizes in panel A are averages of the effects of three different prizes. Table 4, panel B present the same analysis when we consider the effect of different values of the monetary prize. ${ }^{19}$ As above, we are not able to identify any significant interaction between the two types of prizes. In terms of reduction in damage to rice stored (our main outcome of interest), the effect is driven solely by the intermediate valued prize $(500,000$ LAK), with neither lower nor higher prizes capable of motivating changes in behavior that translate into significant reductions in damage.

This apparently counterintuitive result may be explained by the fact that effective rodent control requires continued effort (to address the reproductive behavior of this pest), ideally spread through a large number of households (to address its limited geographical effect). Low prizes do not seem to motivate enough households to devote time to rodent control while, as shown in Figure 1, high prizes do not seem capable of sustaining initial efforts given that they seem to lead to higher rates of drop-out of the contest after the first month. ${ }^{20}$

The values presented in Table 4 allow us to calculate the Benefit-Cost Ratio (BCR) of this intervention. ${ }^{21}$ Here, and in the rest of this paper, we

\footnotetext{
${ }^{19}$ The interpretation of the different variables discussed in the previous footnote carries over to the different values of the monetary prize.

${ }^{20}$ See Figure 1d above, as well as Table B2.

${ }^{21}$ Details of costs and benefits are presented in Appendix C.
} 
Table 4: Evaluating the impact of the contest: ITT estimates

\begin{tabular}{|c|c|c|c|c|c|}
\hline & $\begin{array}{c}(1) \\
\text { Number } \\
\text { of traps } \\
\text { used } \\
\end{array}$ & $\begin{array}{c}(2) \\
\text { Male adults } \\
\text { involved in } \\
\text { rodent control }\end{array}$ & $\begin{array}{c}(3) \\
\text { Male children } \\
\text { involved in } \\
\text { rodent control }\end{array}$ & $\begin{array}{c}(4) \\
\text { Total } \\
\text { number of } \\
\text { rodents culled }\end{array}$ & $\begin{array}{c}(5) \\
\text { Damage } \\
\text { to stored rice } \\
\text { (in } \mathrm{kg}) \\
\end{array}$ \\
\hline \multicolumn{6}{|l|}{ Panel A: ITT estimates } \\
\hline \multirow[t]{2}{*}{ merit $\mathrm{X}$ round } & $\begin{array}{c}5.298^{* *} \\
(2.571)\end{array}$ & $\begin{array}{c}0.175 \\
(0.178)\end{array}$ & $\begin{array}{c}0.227^{* * *} \\
(0.0770)\end{array}$ & $\begin{array}{c}10.51 \\
(16.21)\end{array}$ & $\begin{array}{c}5.164 \\
(8.043)\end{array}$ \\
\hline & {$[0.058]$} & {$[0.378]$} & {$[0.005]$} & {$[0.536]$} & {$[0.560]$} \\
\hline \multirow[t]{2}{*}{ money $\mathrm{X}$ round } & $\begin{array}{l}-0.611 \\
(3.121)\end{array}$ & $\begin{array}{c}0.00824 \\
(0.168)\end{array}$ & $\begin{array}{c}0.180^{* * *} \\
(0.0548)\end{array}$ & $\begin{array}{c}18.88 \\
(18.48)\end{array}$ & $\begin{array}{l}-15.51^{*} \\
(8.338)\end{array}$ \\
\hline & {$[0.852]$} & {$[0.963]$} & {$[0.006]$} & {$[0.344]$} & {$[0.092]$} \\
\hline \multirow[t]{2}{*}{ merit + money $\mathrm{X}$ round } & $\begin{array}{c}4.108 \\
(4.996)\end{array}$ & $\begin{array}{l}-0.199 \\
(0.207)\end{array}$ & $\begin{array}{l}-0.136 \\
(0.095)\end{array}$ & $\begin{array}{l}-11.29 \\
(32.07)\end{array}$ & $\begin{array}{c}4.876 \\
(11.75)\end{array}$ \\
\hline & {$[0.423]$} & {$[0.357]$} & {$[0.180]$} & {$[0.751]$} & {$[0.698]$} \\
\hline $\begin{array}{l}\text { Observations } \\
R^{2} \\
\end{array}$ & $\begin{array}{c}730 \\
0.050 \\
\end{array}$ & $\begin{array}{c}730 \\
0.041 \\
\end{array}$ & $\begin{array}{c}730 \\
0.040 \\
\end{array}$ & $\begin{array}{c}730 \\
0.048 \\
\end{array}$ & $\begin{array}{c}730 \\
0.030 \\
\end{array}$ \\
\hline \multicolumn{6}{|c|}{ Panel B: ITT estimates - by value of prize } \\
\hline merit $\mathrm{X}$ round & $\begin{array}{c}5.298^{* *} \\
(2.586) \\
{[0.058]}\end{array}$ & $\begin{array}{c}0.175 \\
(0.179) \\
{[0.365]}\end{array}$ & $\begin{array}{c}0.227^{* * *} \\
(0.0775) \\
{[0.003]}\end{array}$ & $\begin{array}{c}10.51 \\
(16.30) \\
{[0.537]}\end{array}$ & $\begin{array}{c}5.164 \\
(8.088) \\
{[0.554]}\end{array}$ \\
\hline 250,000 LAK X round & $\begin{array}{l}-5.506 \\
(5.129) \\
{[0.527]}\end{array}$ & $\begin{array}{l}0.0529 \\
(0.157) \\
{[0.759]}\end{array}$ & $\begin{array}{c}0.118 \\
(0.0741) \\
{[0.195]}\end{array}$ & $\begin{array}{l}-2.753 \\
(40.62) \\
{[0.927]}\end{array}$ & $\begin{array}{l}-15.79 \\
(10.77) \\
{[0.235]}\end{array}$ \\
\hline 500,000 LAK X round & $\begin{array}{c}2.261 \\
(2.638) \\
{[0.464]}\end{array}$ & $\begin{array}{c}0.101 \\
(0.205) \\
{[0.657]}\end{array}$ & $\begin{array}{c}0.125^{* *} \\
(0.0597) \\
{[0.198]}\end{array}$ & $\begin{array}{c}20.91 \\
(16.27) \\
{[0.306]}\end{array}$ & $\begin{array}{c}-26.69^{* * *} \\
(9.738) \\
{[0.040]}\end{array}$ \\
\hline 750,000 LAK X round & $\begin{array}{c}1.582 \\
(4.486) \\
{[0.718]}\end{array}$ & $\begin{array}{l}-0.124 \\
(0.213) \\
{[0.610]}\end{array}$ & $\begin{array}{c}0.294^{* * *} \\
(0.0672) \\
{[0.004]}\end{array}$ & $\begin{array}{c}38.60 * * \\
(14.83) \\
{[0.048]}\end{array}$ & $\begin{array}{l}-4.700 \\
(9.155) \\
{[0.668]}\end{array}$ \\
\hline $250,000 \mathrm{LAK}+$ merit $\mathrm{X}$ round & $\begin{array}{l}10.49 \\
(7.194) \\
{[0.317]}\end{array}$ & $\begin{array}{l}-0.198 \\
(0.229) \\
{[0.426]}\end{array}$ & $\begin{array}{c}-0.0346 \\
(0.102) \\
{[0.768]}\end{array}$ & $\begin{array}{l}-20.02 \\
(42.68) \\
{[0.645]}\end{array}$ & $\begin{array}{c}11.91 \\
(20.06) \\
{[0.634]}\end{array}$ \\
\hline $500,000 \mathrm{LAK}+$ merit $\mathrm{X}$ round & $\begin{array}{l}-4.105 \\
(8.773) \\
{[0.652]}\end{array}$ & $\begin{array}{l}-0.315 \\
(0.256) \\
{[0.269]}\end{array}$ & $\begin{array}{c}-0.0419 \\
(0.0996) \\
{[0.710]}\end{array}$ & $\begin{array}{l}-2.028 \\
(68.31) \\
{[0.969]}\end{array}$ & $\begin{array}{c}11.40 \\
(12.75) \\
{[0.437]}\end{array}$ \\
\hline $750,000 \mathrm{LAK}+$ merit $\mathrm{X}$ round & $\begin{array}{c}5.202 \\
(6.068) \\
{[0.492]}\end{array}$ & $\begin{array}{c}-0.0864 \\
(0.258) \\
{[0.753]}\end{array}$ & $\begin{array}{c}-0.316^{* *} \\
(0.125) \\
{[0.036]}\end{array}$ & $\begin{array}{l}-14.74 \\
(27.26) \\
{[0.645]}\end{array}$ & $\begin{array}{l}-7.723 \\
(14.61) \\
{[0.673]}\end{array}$ \\
\hline Observations & 730 & 730 & 730 & 730 & 730 \\
\hline$R^{2}$ & 0.059 & 0.050 & 0.059 & 0.079 & 0.063 \\
\hline Control mean & 29.200 & 1.037 & 0.213 & 69.343 & 60.541 \\
\hline
\end{tabular}


will focus solely on monetary prizes, given that merit awards do not seem to have any effect in terms of reducing losses in storage. Costs include the salary and the transportation cost of the field staff (for example, to organize village meetings at the start and the end of the contest), communication and advertisement expenses as well as payments for monitoring of the contest at village level and, finally, the prizes. We do not include estimates of the value of time allocated to rodent control. We measure the benefits of the contest using the ITT estimates of reduced damage, valued at the price of rice in April 2018 (mid-year between harvests). The BCR for money prizes is 4.95 (7.42 in the case of the 500,000 LAK prize) a value that is relatively high, but plausible given the simplicity of this contest and its low cost. Given that $85 \%$ of the households did not participate in the contest, it is likely that much of the benefit can be attributed to reductions in losses by non-participants, an aspect that we address in section 5 .

\section{$5 \quad$ Spillovers}

\subsection{Local savings}

The existence of spillovers from rodent control is at the origin of the need to promote coordination through the contest we piloted, where the prizes offered are expected to reward participants for the external benefits from their actions. Given that every household was eligible to participate in the contest in villages where prizes were offered, the quantification of the benefits to non-participants requires addressing self-selection into the contest. We do that by estimating the probability of participating in the contest, ie, 
the propensity score. We then use these estimates to match participants and non-participants in treatment villages with observationally identical respondents in control villages. ${ }^{22}$ More formally, we estimate the direct effect of this competition as

$$
\tau^{d}=E[E(y(1) \mid T=1, P(X))-E(y(0) \mid T=0, P(X))]
$$

and the spillover (or indirect) effect as

$$
\tau^{i}=E[E(y(0) \mid T=1, P(X))-E(y(0) \mid T=0, P(X))]
$$

where $y(1)$ and $y(0)$ is the outcome for households who participated and did not participate in the contest, respectively, and $P(X)$ is the probability of participating in the contest in treated villages, given observable characteristics $X$, including pre-contest self-assessed importance of damage (proxying for lagged measures of our outcome) as well as variables that measure labour availability and assets (as proxies for the opportunity cost of time), past experience with rodent control in the dry season, and expected benefits (knowledge about benefits from rodent control by neighbours, extent of rice rationing in the past). ${ }^{23}$ Given the relatively small sample, we use kernel weights (?), calculated using the estimates of the propensity score, to estimate the similarity between different observations. ${ }^{24}$ Results are presented in Table 5, columns 1-2.

\footnotetext{
${ }^{22}$ See ? for a discussion of this approach.

${ }^{23}$ Estimates of the propensity score are presented in Table B6.

${ }^{24}$ The use of weights explains why direct and spillover effects are, each, larger than the estimates presented in Table 4 .
} 
Table 5: Evaluating the impact of the contest on rice losses: spillovers

\begin{tabular}{|c|c|c|c|c|}
\hline VARIABLES & $\begin{array}{c}(1) \\
\text { Kernel } \\
\text { participant }\end{array}$ & $\begin{array}{c}(2) \\
\text { Kernel } \\
\text { non-participant }\end{array}$ & $\begin{array}{c}(3) \\
\text { Kernel } \\
\text { participant }\end{array}$ & $\begin{array}{c}(4) \\
\text { Kernel } \\
\text { non-participant }\end{array}$ \\
\hline money $\mathrm{X}$ round & $\begin{array}{l}-24.18 \\
(19.39)\end{array}$ & $\begin{array}{c}-16.35 \\
(10.12)\end{array}$ & $\begin{array}{c}-8.011 \\
(12.36)\end{array}$ & $\begin{array}{c}-23.89^{* *} \\
(10.22)\end{array}$ \\
\hline merit + money $\mathrm{X}$ round & $\begin{array}{c}16.86 \\
(22.16)\end{array}$ & $\begin{array}{c}7.711 \\
(8.692)\end{array}$ & $\begin{array}{l}-3.705 \\
(10.77)\end{array}$ & $\begin{array}{c}20.27 \\
(12.92)\end{array}$ \\
\hline $\begin{array}{l}\text { Observations } \\
R^{2}\end{array}$ & $\begin{array}{c}228 \\
0.057\end{array}$ & $\begin{array}{c}468 \\
0.031\end{array}$ & $\begin{array}{c}330 \\
0.036\end{array}$ & $\begin{array}{c}304 \\
0.042\end{array}$ \\
\hline
\end{tabular}

Reflecting the importance of externalities associated with this problem, the estimates of average spillover are fairly large $(-16.3 \mathrm{~kg}$, or $30 \%$ of average loss in control villages), and only slightly smaller than the gains reported by participants themselves $(-24.2 \mathrm{~kg}$, or $40 \%$ of the average damage in control villages, although this effect is imprecisely estimated, reflecting the relatively small number of participants in the contest).

We can get more precise estimates of spillover effects by using the knowledge that rodent mobility is limited, given that black rats do not forage beyond $100 \mathrm{~m}$ from their nests. This suggests that we should only expect to see an indirect effect among non-participants who have participating neighbours within that radius. Results from this disaggregation of the indirect effect are presented in Table 5, columns 3-4: non-participants who do not have neighbours participating in the contest do not benefit from it, while those who have such neighbors benefit as much as participants. 


\subsection{Aggregating savings: market effects}

A natural follow-up question is whether these savings at household level translate into changes in market prices when markets are isolated, as is the case of villages without all-year roads during the wet season. The savings identified above should either lead to an increase in supply of rice (for households that are net-sellers of rice) and a reduction in demand (by households that are net-buyers of rice, who will now reduce their need to rely on the local market). The net effect is that we would expect to see lower prices in isolated local markets in villages that were allocated to monetary prizes, particularly as rice stocks are progressively exhausted and an increasing number of households face the need to buy rice in the local market (i.e, as the wet season progresses).

To quantify this effect, we use data on monthly price of rice from local millers for the period January 2017 to December 2018 in 35 villages. ${ }^{25}$ The wet season runs April/May to September, with rice being harvested in October-November. Given we did not follow a block randomized design, 14 out of the 17 villages that do not have an all-year road that can be used by a car or a truck were allocated to monetary prizes (either alone or in combination with merit prizes), leaving only 3 as control - a small number, that suggests caution in interpreting these results. Figure 2 plots the estimates of the effect of monetary prizes on rice prices for the period

\footnotetext{
${ }^{25}$ This data was first collected in May 2018. Data for the period January 2017 to May 2018 is recall data. Data for the period June 2018 to December 2018 was collected at the end of each month, via telephone interview. One village did not have a local miller and is not included in the analysis.
} 
Figure 2: The effect of monetary prizes on rice prices in isolated markets. Bars represent 95\% CI.

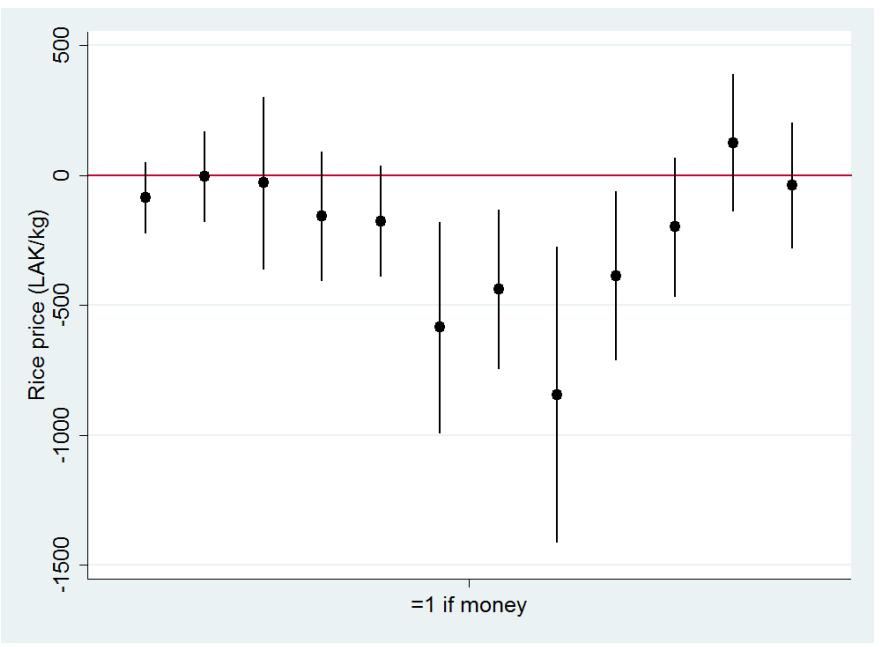

January-December 2018. ${ }^{26}$

We can estimate this effect using pooled data for all months during the wet season (May-October) and the following model:

$$
\begin{aligned}
& P_{t, 18}=\alpha+\beta_{1} P_{t, 17}+\beta_{2} \text { Money }+\beta_{3}(\text { Money }+ \text { Merit })+\beta_{4} \text { Isolated }+ \\
& +\beta_{5}(\text { Money } \times \text { Isolated })+\beta_{6}((\text { Money }+ \text { Merit }) \times \text { Isolated })+\theta X
\end{aligned}
$$

and we are mostly interested in the estimates of $\beta_{5}$, the effect of offering a monetary prize in villages that do not have access to roads during wet season, conditional on previous year price in month $t\left(P_{t, 17}\right)$ and other potential

\footnotetext{
${ }^{26}$ The estimates presented are the effect of running a contest with monetary prizes, conditional on having no access to car or truck during wet season $(\mathrm{N}=17)$, obtained using the following model: $P_{t, 18}=\alpha+\beta_{1} P_{t, 17}+\beta_{2}$ Money $+\beta_{3}$ (Money + Merit $)+\theta X$ where $X$ include variables that proxy for productive capacity (upland, restrictions due to land planning) and capacity to manage rice demand (presence of rice bank).
} 
confounders $(X)$. The results are presented in Table 6 .

Table 6: The effect of monetary prizes on the price of rice in isolated markets

\begin{tabular}{|c|c|c|c|}
\hline \multirow{3}{*}{$\begin{array}{l}\text { Variables } \\
\text { price (2017) }\end{array}$} & (1) & $(2)$ & $(3)$ \\
\hline & \multicolumn{3}{|c|}{ Rice price $(\mathrm{LAK} / \mathrm{kg})$} \\
\hline & $0.964^{* * *}$ & $0.985^{* * *}$ & $0.816^{* * *}$ \\
\hline & $(0.0476)$ & $(0.0445)$ & $(0.0806)$ \\
\hline \multirow[t]{2}{*}{ money } & 32.26 & 72.14 & 34.17 \\
\hline & $(43.38)$ & $(46.15)$ & $(53.35)$ \\
\hline \multirow[t]{2}{*}{ merit + money } & -72.86 & -84.34 & 9.465 \\
\hline & $(114.9)$ & $(115.9)$ & $(144.5)$ \\
\hline \multirow[t]{2}{*}{ isolated } & 134.7 & $486.6^{* * *}$ & $362.8^{* * *}$ \\
\hline & $(87.03)$ & $(82.76)$ & $(101.5)$ \\
\hline \multirow[t]{2}{*}{ money $\mathrm{X}$ isolated } & -151.1 & $-471.3^{* * *}$ & $-348.7^{* * *}$ \\
\hline & $(104.2)$ & $(86.94)$ & $(105.9)$ \\
\hline \multirow[t]{2}{*}{ merit + money $\mathrm{x}$ isolated } & 206.7 & 169.5 & 118.2 \\
\hline & $(130.6)$ & $(126.9)$ & $(162.0)$ \\
\hline \multirow[t]{2}{*}{ upland } & & 14.40 & 6.182 \\
\hline & & $(45.79)$ & $(51.99)$ \\
\hline \multirow[t]{2}{*}{ Land and Forest Allocation } & & $-325.9^{* * *}$ & $-260.6^{* * *}$ \\
\hline & & $(49.96)$ & $(64.13)$ \\
\hline \multirow[t]{2}{*}{ rice bank } & & 51.86 & 53.22 \\
\hline & & $(32.25)$ & $(46.70)$ \\
\hline \multirow[t]{2}{*}{ constant } & 87.82 & $262.2^{* *}$ & $754.9 * * *$ \\
\hline & $(129.8)$ & $(108.7)$ & $(194.9)$ \\
\hline Month FE & no & no & yes \\
\hline Observations & 189 & 189 & 189 \\
\hline Number of villages & 27 & 27 & 27 \\
\hline
\end{tabular}

The main conclusion is that the contest led to significant reductions in the price of rice, presumably by increasing the amount of rice available supplied to the local market by households who are net-sellers and reducing the demand by those who do not have enough rice to last between two harvests (and are net-buyers): the average reduction of approximately $500 \mathrm{LAK} / \mathrm{kg}$ in our preferred specification (with control variables, in column 2) is roughly $20 \%$ of the average price of rice during wet season in isolated control villages. 


\section{Conclusion and discussion}

The dispersion of invasive species (and, more generally, pests) over the landscape raises important challenges to control efforts, in particular the need to coordinate multiple participants, which increases the scope for free-riding behavior. In this article, we evaluate the impact of one approach that directly addresses that difficulty: we organize a contest for different prizes, with the aim of rewarding those who engage in control activities for the externalities that they create.

We apply this approach to the problem of rodent control, a recognized pest in much of Asia, responsible for large losses to rice production, both before and after harvest. The results of the experimental evaluation of the impact of this approach in terms of reduced losses to stored rice are quite encouraging. Relatively small monetary prizes can lead to reductions in losses of approximately $25 \%$ of those reported in control villages. On the other hand, merit awards (the default incentive in our context) have no noticeable effect.

Our results also show that localized spillovers matter greatly, and that non-participants who happen to have participants as relatively close neighbours (less than 100 meters, the radius of mobility from their nests for the black rat) benefit as much as participants themselves. On the other hand, non-participants who do not have such neighbors do not benefit at all. In isolated markets, where prices are formed by local supply and demand, the reduction in losses is important enough to reduce rice prices, potentially with important consequences for the welfare of food insecure households. 
By design, we evaluated a contest with simple rules, with monitoring delegated to villagers themselves. As a result, scaling-up of this type of program is not inhibited by human resource constraints, although it may still be limited by budgetary constraints.

Before considering its expansion, it is important to notice that our results also show that small variations in the design of this contest (in this case, variation in prize) matter and in relatively unpredictable ways: in our sample, only intermediate sized prices cause reductions in losses. The lack of an effect of higher prizes may be explained by very high levels of effort at the start of the competition by a few competitors, which act to discourage effort of a relatively high number of participants in subsequent periods (as they recognize early on that they have no chance of winning the prize).

Given the need for continued and widespread control effort in order to reduce pest pressure, this result suggests that other variations may be even more effective in promoting behavioural change. For example, a contest that disburses the same total amount as a series of monthly prizes (rather than as one large prize at the end) or as a set of different valued prizes, might potentially limit the discouragement of those participants who are initial under-performers (as they would now have another chance to win a prize, either in the near future or to receive a lower valued prize). Our results are unable to answer such questions, but invite further work.

Similarly, we noted before the similarity between proposed rodent control technologies and Integrated Pest Management. The feasibility of extending this approach to other pests that exhibit similar problems of externalities is an empirical question, the answer to which likely also depends on the 
feasibility of monitoring control effort. Given the large importance of food loss, both before and after harvest, as well as the recognized negative ecological impacts of invasive species, further consideration of practical ways of internalizing the benefits of pest control seem warranted. 


\section{A Protocol of the village meeting}

I want to welcome you all to this meeting. In this meeting, we will launch a pest rodent intervention for the project Food Security in the Northern Uplands of Lao PDR.

My name is .... I work for ... and I am based in ....

The project Food Security in the Northern Uplands of Lao PDR is implemented by the National University of Laos together with other institutions from Australia. The Australian institutions include Monash University, The University of Sydney and James Cook University. The agency funding this project is the Australian Centre for International Agricultural Research (ACIAR).

The goal of this pest rodent intervention is to increase pest rodent control in Luangprabang province in the dry season. Pest rodents are those rodents that enter the storage huts where the harvested rice meant for household consumption is stored. They eat and contaminate the stored rice. Data collected by this project for Luangprabang shows that more than $20 \%$ of the harvest is on average lost to pest rodents. This equals 5 bags of rice for each household. A large share of this damage happens in the dry season.

Five bags of rice is a big loss. To reduce this damage by pest rodents, it is important that rodents are culled continuously and collectively.

Research showed that most of the damage in the dry season is done by the black rat. The black rat is known in Luangprabang by various names, such as Nhu Khee, Nhu Ban, Nhu Dam, Nhu Na, Nhu (Na) Tong-khaw. On the pictures of this poster you can see different black rats.

I am sure you all know the black rat, but let me repeat some facts about the black rat.

The black rat lives in both the fields and in the village. It breads immediately when enough food is available. This is mostly in the field at the end of the rain 
season or in the villages at the beginning of the dry season. In a yearly cycle the population is the largest at the beginning of the dry season.

It is a medium size rat. Head and body are together on average $17 \mathrm{~cm}$ long and the tail is around $18 \mathrm{~cm}$ long. Its dorsum is reddish grey brown and the ventrum is white to cream. The tail is dark brown. And the ears of the black rat are large.

To reduce the damage from the black rat in your village, we would like to offer prizes to the households that kill most rats from now until Pi Mai. I will explain now the rules and the procedure of the contest:

- Every person in the village can participate in the contest. There is no age requirement and also people who were not present in this meeting can participate. The only criteria is that participants have to be residents of this village.

- Participants of this contest should only cull black rats. If you only cull rodents in the villages and in the fields, the main pest rodents are black rats. It is very important not to cull rodents in the forests for the contest. In the forests there are also endangered rodent species, which fulfill important ecosystem services and are not responsible for the damage in the storage huts. If those rodents are hunted to extinction then this will have negative consequences for the environment.

- The black rat should be hunted or culled with traps. No rodenticides or other harmful chemical products should be used.

- The tail of the Black Rat will be used as evidence of the cull.

- There will be prizes for the three person that culled most black rats in the contest. The prizes are [report the prize selected for this village].

The contest will be held from now until Pi Mai (Lao New Year).

- There will also be the possibility to disqualify somebody from the contest, if this person is not playing by the rules. You will have to decide if someone is not playing fair - but we will not be involved.

- This is a contest between the people of this village. If somebody is not playing according to the rules, he or she is cheating the other people in the village. For 
instance, we heard that when there were bounty schemes, some people started to bread rodents and they submitted those tails to get more cash. In this contest, if people do that and submit the rat tails of breaded black rats, those people are cheating the other people in the village. Because the person who contributes hunted rodents and thus reduces the damage of black rats in the village and he will not win, but the person who was cheating. This is not fair. Thus, if somebody knows that another person is not playing by the rules, they have to tell this to the village representative and he can disqualify the person from the contest.

There is one last thing I want to do in this meeting. I want to ask you to select one person, who should be responsible for counting and reporting the rat tails. Please select one person that you all trust.

[After the village representative was selected]

- The village representative will be responsible for counting the rat tails and writing down how many black rats a person culled. At the end of every month, he will announce a day when he counts tails and records the numbers. After he counted the tails, the person who culled them is responsible for disposing them.

Do you have any questions?

[After the questions]

This is a poster which summarizes the most important rules of the contest, please take a copy for yourselves and keep it in your house.

Thank you very much for your participation in the meeting and your attention. 


\section{B Additional results}

Table B1: Evolution of participation and effort

\begin{tabular}{|c|c|c|c|c|}
\hline & \multicolumn{3}{|c|}{ Participants } & April \\
\hline Merit & 44 & 21 & 15 & 30 \\
\hline 250,000 & 24 & 16 & 10 & 15 \\
\hline 500,000 & 77 & 26 & 15 & 23 \\
\hline 750,000 & 61 & 27 & 16 & 18 \\
\hline \multicolumn{5}{|c|}{ Culled rodents - average } \\
\hline Merit & 30 & 23 & 42 & 14 \\
\hline 250,000 & 101 & 35 & 32 & 44 \\
\hline 500,000 & 60 & 72 & 62 & 66 \\
\hline 750,000 & 114 & 65 & 35 & 57 \\
\hline
\end{tabular}

Table B2: Participation and effort after the first month of the contest

\begin{tabular}{|c|c|c|c|}
\hline \multirow{6}{*}{ []article } & VARIABLES & $\begin{array}{c}(1) \\
\text { dropall }\end{array}$ & $\begin{array}{c}(2) \\
\text { effort3 }\end{array}$ \\
\hline & dist_jan & $\begin{array}{c}0.00437^{* * *} \\
(0.00142)\end{array}$ & $\begin{array}{c}-0.203^{* * *} \\
(0.0680)\end{array}$ \\
\hline & dist_jan2 & $-1.08 \mathrm{e}-05^{* * *}$ & $0.000439 * * *$ \\
\hline & Constant & $\begin{array}{c}0.242^{* * *} \\
(0.0607)\end{array}$ & $\begin{array}{c}24.29^{* * *} \\
(5.889)\end{array}$ \\
\hline & Observations & 242 & 242 \\
\hline & R-squared & 0.103 & 0.082 \\
\hline
\end{tabular}




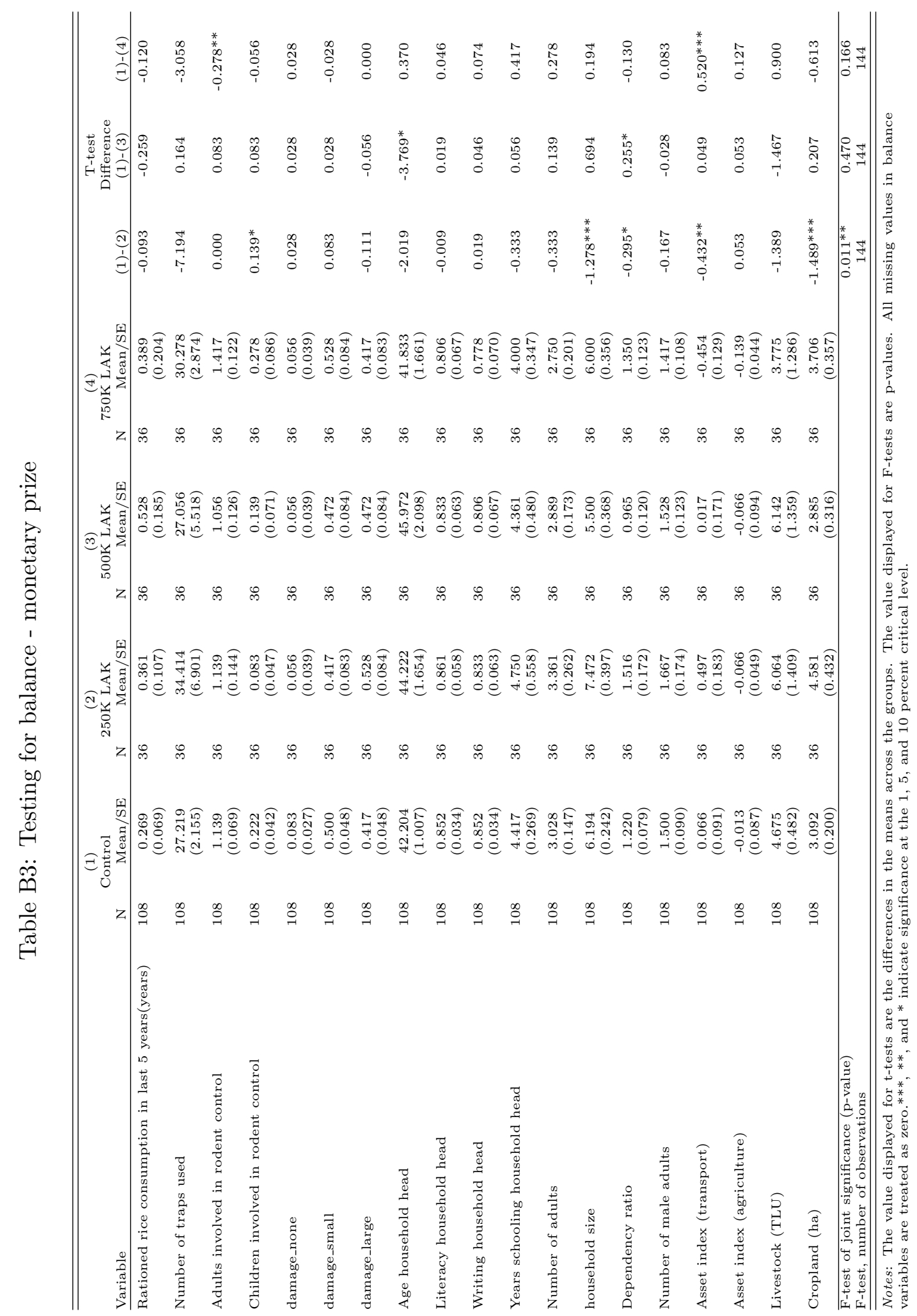




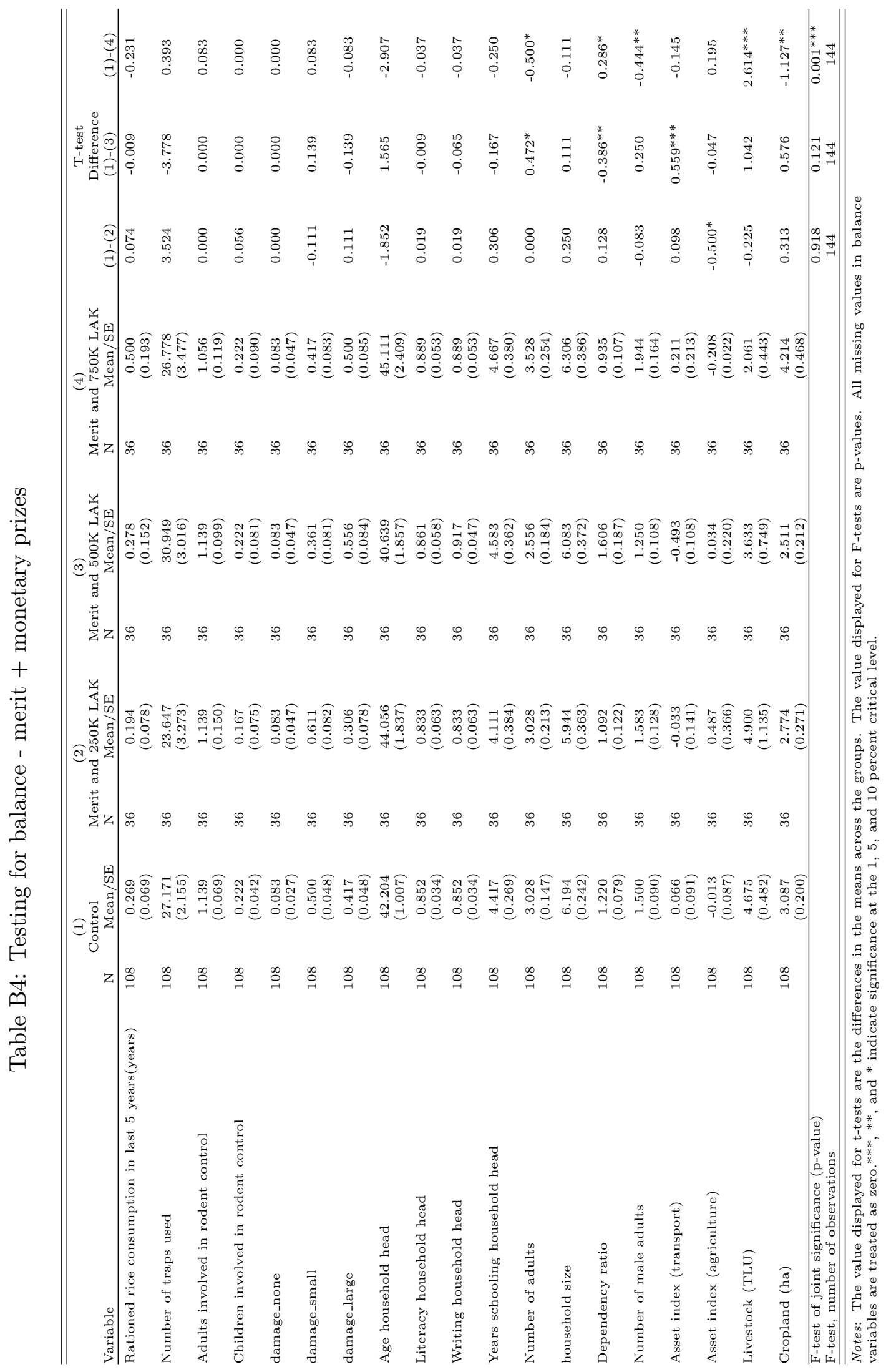


Table B5: Evaluating the impact of the contest: ITT estimates, with control

\begin{tabular}{|c|c|c|c|c|c|}
\hline & $\begin{array}{c}\text { (1) } \\
\text { Number } \\
\text { of traps } \\
\text { used }\end{array}$ & $\begin{array}{c}(2) \\
\text { Male adults } \\
\text { involved in } \\
\text { rodent control }\end{array}$ & $\begin{array}{c}(3) \\
\text { Male children } \\
\text { involved in } \\
\text { rodent control }\end{array}$ & $\begin{array}{c}\text { (4) } \\
\text { Total } \\
\text { number of } \\
\text { rodents culled }\end{array}$ & $\begin{array}{c}(5) \\
\text { Damage } \\
\text { to stored rice } \\
\text { (in } \mathrm{kg})\end{array}$ \\
\hline \multicolumn{6}{|l|}{ Panel A: ITT estimates } \\
\hline merit $\mathrm{X}$ round & $\begin{array}{l}4.703^{*} \\
(2.688)\end{array}$ & $\begin{array}{c}0.167 \\
(0.183)\end{array}$ & $\begin{array}{c}0.221^{* * *} \\
(0.0777)\end{array}$ & $\begin{array}{c}7.927 \\
(16.49)\end{array}$ & $\begin{array}{c}5.652 \\
(8.378)\end{array}$ \\
\hline money $\mathrm{X}$ round & $\begin{array}{c}-0.554 \\
(3.194)\end{array}$ & $\begin{array}{c}-0.000373 \\
(0.172)\end{array}$ & $\begin{array}{c}0.186^{* * *} \\
(0.0562)\end{array}$ & $\begin{array}{c}19.63 \\
(19.42)\end{array}$ & $\begin{array}{l}-14.94^{*} \\
(8.466)\end{array}$ \\
\hline merit + money $\mathrm{X}$ round & $\begin{array}{c}4.691 \\
(5.152)\end{array}$ & $\begin{array}{l}-0.186 \\
(0.211)\end{array}$ & $\begin{array}{c}-0.132 \\
(0.0963)\end{array}$ & $\begin{array}{c}-9.891 \\
(32.96)\end{array}$ & $\begin{array}{c}3.657 \\
(12.03)\end{array}$ \\
\hline $\begin{array}{l}\text { Observations } \\
R^{2}\end{array}$ & $\begin{array}{c}714 \\
0.510\end{array}$ & $\begin{array}{c}714 \\
0.422\end{array}$ & $\begin{array}{c}714 \\
0.059\end{array}$ & $\begin{array}{c}714 \\
0.271\end{array}$ & $\begin{array}{c}714 \\
0.056\end{array}$ \\
\hline \multicolumn{6}{|c|}{ Panel B: ITT estimates - by value of prize } \\
\hline merit $\mathrm{X}$ round & $\begin{array}{l}4.703^{*} \\
(2.771)\end{array}$ & $\begin{array}{c}0.167 \\
(0.189)\end{array}$ & $\begin{array}{c}0.221^{* * *} \\
(0.0801)\end{array}$ & $\begin{array}{c}7.927 \\
(17.00)\end{array}$ & $\begin{array}{c}5.652 \\
(8.637)\end{array}$ \\
\hline 250,000 LAK X round & $\begin{array}{l}-5.496 \\
(5.415)\end{array}$ & $\begin{array}{l}0.0559 \\
(0.167)\end{array}$ & $\begin{array}{c}0.121 \\
(0.0768)\end{array}$ & $\begin{array}{l}-2.422 \\
(43.52)\end{array}$ & $\begin{array}{l}-13.63 \\
(9.922)\end{array}$ \\
\hline 500,000 LAK X round & $\begin{array}{c}2.374 \\
(2.818)\end{array}$ & $\begin{array}{l}0.0831 \\
(0.207)\end{array}$ & $\begin{array}{c}0.133^{*} \\
(0.0681)\end{array}$ & $\begin{array}{c}22.41 \\
(18.49)\end{array}$ & $\begin{array}{c}-27.86^{* *} \\
(10.41)\end{array}$ \\
\hline 750,000 LAK X round & $\begin{array}{c}1.660 \\
(4.633)\end{array}$ & $\begin{array}{l}-0.129 \\
(0.223)\end{array}$ & $\begin{array}{c}0.294^{* * *} \\
(0.0699)\end{array}$ & $\begin{array}{c}38.58^{* *} \\
(15.57)\end{array}$ & $\begin{array}{l}-4.817 \\
(9.592)\end{array}$ \\
\hline $250,000 \mathrm{LAK}+$ merit $\mathrm{X}$ round & $\begin{array}{c}11.15 \\
(7.558)\end{array}$ & $\begin{array}{l}-0.198 \\
(0.241)\end{array}$ & $\begin{array}{r}-0.0318 \\
(0.106)\end{array}$ & $\begin{array}{l}-17.79 \\
(45.55)\end{array}$ & $\begin{array}{c}9.152 \\
(20.18)\end{array}$ \\
\hline $500,000 \mathrm{LAK}+$ merit $\mathrm{X}$ round & $\begin{array}{l}-3.841 \\
(9.404)\end{array}$ & $\begin{array}{l}-0.288 \\
(0.262)\end{array}$ & $\begin{array}{c}-0.0328 \\
(0.106)\end{array}$ & $\begin{array}{l}-1.903 \\
(73.47)\end{array}$ & $\begin{array}{c}11.64 \\
(13.60)\end{array}$ \\
\hline $750,000 \mathrm{LAK}+$ merit $\mathrm{X}$ round & $\begin{array}{c}5.797 \\
(6.317)\end{array}$ & $\begin{array}{c}-0.0786 \\
(0.270)\end{array}$ & $\begin{array}{c}-0.309^{* *} \\
(0.129)\end{array}$ & $\begin{array}{l}-12.16 \\
(28.27)\end{array}$ & $\begin{array}{c}-8.211 \\
(15.26)\end{array}$ \\
\hline Observations & 714 & 714 & 714 & 714 & 714 \\
\hline$R^{2}$ & 0.223 & 0.453 & 0.185 & 0.272 & 0.161 \\
\hline Control mean & 29.200 & 1.037 & 0.213 & 69.343 & 60.541 \\
\hline
\end{tabular}


Table B6: Participation in contest - propensity score

[]article

\begin{tabular}{|c|c|}
\hline VARIABLES & $\begin{array}{c}(1) \\
\text { First step }\end{array}$ \\
\hline Small damage to stored rice by rodents (previous DS) & $\begin{array}{c}0.298 \\
(0.558)\end{array}$ \\
\hline Large damage to stored rice by rodents (previous DS) & $\begin{array}{c}0.583 \\
(0.553)\end{array}$ \\
\hline merit + money & $\begin{array}{c}-0.445^{*} \\
(0.235)\end{array}$ \\
\hline household size & $\begin{array}{l}-0.126 \\
(0.142)\end{array}$ \\
\hline Number of adults & $\begin{array}{c}0.233 \\
(0.254)\end{array}$ \\
\hline Asset index (transport) & $\begin{array}{c}0.00985 \\
(0.112)\end{array}$ \\
\hline Asset index (agriculture) & $\begin{array}{c}0.149^{*} \\
(0.0828)\end{array}$ \\
\hline Rodent outbreak in last 10 years & $\begin{array}{l}0.0928 \\
(0.180)\end{array}$ \\
\hline RECODE of neigh_bene_ds (When I am successful in controlling rats in my residenc & $\begin{array}{l}0.0576 \\
(0.156)\end{array}$ \\
\hline RECODE of own_bene_ds (If my neighbors spend more time controlling rats during t & $\begin{array}{l}-0.243 \\
(0.193)\end{array}$ \\
\hline I only start rat control in my storage in the dry season when I see that rats ca & $\begin{array}{c}-0.0386 \\
(0.270)\end{array}$ \\
\hline I control rats even without seeing any sign of damage to the stored rice in the & $\begin{array}{l}-0.336 \\
(0.260)\end{array}$ \\
\hline Rationed rice consumption in last 5 years(years) & $\begin{array}{c}-0.0246 \\
(0.134)\end{array}$ \\
\hline Dependency ratio & $\begin{array}{c}0.226 \\
(0.336)\end{array}$ \\
\hline Observations & 216 \\
\hline Pseudo R2 & 0.0678 \\
\hline
\end{tabular}




\section{Cost-Benefit Analysis}

Costs per village are presented in Table C1. The project hired field staff, who were responsible for facilitating village meetings and hand over the prizes. Their monthly salary was 3,000,000 LAK. The average fuel cost were 7,500 LAK per village per person. On April 1st, 2018, the exchange rate for 10,000 LAK was 1.202 USD.

Table C1: Costs

\begin{tabular}{llll}
\hline \hline Item & Description & Cost estimates & Total \\
\hline Organization & $2 \frac{1}{2}$ days for setup and finish & $18 * 360.7$ USD / 20 & \\
& Two trips to each of the 18 villages & $18 * 0.90$ USD * 2 & \\
& Communication expenses & $18 * 0.6$ USD & 367.9 \\
Advertisement & Cost of posters & $18 * 1.9$ USD & 34.6 \\
Other costs & Allowance for local monitor & $18 * 12.0$ USD & 216.4 \\
Prizes & winner & $6 * 30.06+6 * 60.11$ & \\
& & $+6 * 90.17$ & 1298.4 \\
\hline Total & lottery & $18 * 12.0$ USD & 1917.3 \\
\hline \hline
\end{tabular}

Table C2: Benefits

\begin{tabular}{llll}
\hline \hline Item & Description & Cost estimates & Total \\
\hline Beneficiaries & $\begin{array}{l}\text { Households in treated villages } \\
\text { Impact }\end{array}$ & $\begin{array}{l}\text { Reduced damage to stored rice in } \\
\text { the dry season }\end{array}$ & 1412 \\
Price of rice & $\begin{array}{l}\text { Average price of unshelled rice in } \\
\text { April } 2018\end{array}$ & USD $/ \mathrm{kg}$ & 0.29 \\
\hline Total & $1412^{*} 15.51^{*} 0.29 \mathrm{USD} / \mathrm{kg}$ & & 6,433 \\
\hline
\end{tabular}

